\title{
VALIDAÇÃO DE MODELOS MATEMÁTICOS PARA PREDIÇÃO DE CONSUMO VOLUNTÁRIO E GANHO EM PESO DE BOVINOS
}

\author{
VALIDATION OF MATHEMATICAL MODELS FOR PREDICTION OF VOLUNTARY \\ CONSUMPTION AND WEIGHT GAIN OF BEEF CATTLE
}

\author{
Rezende, P.L.P. ${ }^{1 *}$, Neto, M.D.F. ${ }^{1 A}$, Restle, J. ${ }^{2}$, Fernandes, J.J.R. ${ }^{3 A}$, Pádua, J.T. ${ }^{3 B}$ \\ e Queiroz, G.A.B. ${ }^{3}$
}

\begin{abstract}
'Universidade Federal de Goiás. Campus Samambaia. Goiânia-GO. Brasil. *pedrozootec@hotmail.com; Amarcondes_dias@hotmail.com

${ }^{2}$ Conselho Nacional de Desenvolvimento Científico e Tecnológico. CNPq. Brasil. jorestle@terra.com.br ${ }^{3}$ Escola de Veterinária. Universidade Federal de Goiás. Brasil. Ajuliano@vet.ufg.br; Bteodoro@vet.ufg.br
\end{abstract}

Palavras chave adicionais

CNCPS. NRC. Confinamento. Exigências.

\section{RESUMO}

Avaliou-se a utilização das equações do Cornell Net Carbohydrate and Protein System (CNCPS) e Nacional Research Council (NRC) nível 1 para predição de consumo de matéria seca e ganho em peso médio diário em condições tropicais de confinamento. Utilizou-se 23 bovinos mestiços Holandês/Zebu confinados em baias individuais com idade média de 20 meses e $260 \mathrm{~kg}$ de peso vivo no início do experimento. As dietas experimentais eram isonitrogenadas compostas por dois níveis de ingestão de energia com 50 ou $80 \%$ de inclusão de concentrado na base da matéria seca para os tratamentos médio (TM) e alto (TA), respectivamente. Observou-se respostas variáveis dos valores observados e preditos de consumo de matéria seca e ganho em peso em função dos níveis alimentares sendo que as melhores predições de consumo foram para o tratamento de médio nível de concentrado em que as equações de regressão apresentaram $R^{2}=$ 0,61 e 0,63 para o CNCPS e NRC, respectivamente. Os modelos foram ineficientes para predição do consumo de matéria seca no tratamento de alta inclusão de concentrado e não apresentaram predição acurada de ganho em peso médio diário em nenhuma das condições experimentais analisadas.

\section{SUMMARY}

We evaluated the use of equations of the

\author{
ADDITIONAL KEYWORDS \\ CNCPS. NRC. Feedlot. Requirements.
}

Cornell Net Carbohydrate and Protein System (CNCPS) and National Research Council (NRC) level 1 to predict the dry matter intake and daily weight gain in tropical conditions of feedlot. We used 23 crossbred steers Holstein / Zebu kept in individual stalls with a mean age of 20 months and $260 \mathrm{~kg}$ live weight at the start of the experiment. The experimental diets were isonitrogenous composed of two levels of energy intake with 50 or $80 \%$ of concentrate in dry matter basis for treatments medium (TM) and high (TA), respectively. Observed variable responses between the observed and predicted values for dry matter intake and weight gain depending on level of concentrate. The best estimate of dry matter intake occurred for the treatment of middle level of concentrate on which the regression equations presented $R^{2}=0.61$ and 0.63 for the CNCPS and NRC, respectively. The models were inefficient for predicting dry matter intake in the treatment of high concentrate inclusion and did not present accurate prediction of daily weight gain in any experimental conditions analyzed.

\section{INTRODUÇÃO}

Os modelos matemáticos são utilizados como ferramentas para estimar as exigências dos animais e o valor nutritivo dos alimentos em cada cenário de produção agrícola e, 
portanto, tem um papel importante no fornecimento informações que podem ser utilizadas no processo de tomada de decisão objetivando aperfeiçoar a eficiência técnica e econômica do sistema de alimentação de bovinos de corte.

Um modelo matemático integrado de nutrição animal é definido como um conjunto de coeficientes de transferência e equações que descrevem as diversas funções fisiológicas dos animais (Gill et al., 1989). Estão incluídos nestes modelos os requerimentos teciduais (manutenção, crescimento, gestação, lactação e tecidos de reserva) e o fornecimento de nutrientes (ingestão de matéria seca, carboidratos, fração protéica bem como suas características de digestão e taxa de passagem, crescimento microbiano, digestão intestinal e metabolismo pós absortivo de nutrientes).

A finalidade de um modelo de simulação é descrever matematicamente a resposta de cada compartimento ou vários compartimentos ligados a uma variável ou combinação de variáveis. Um dos maiores problemas na construção de modelos matemáticos é o nível de agregação das equações (Tedeschi et al., 2005).

O Cornell Net Carbohydrate and Protein System (CNCPS) e o Nacional Research Council (NRC) nível 1 são modelos americanos idealizados para ajustar os requerimentos e a utilização de nutrientes dentro de uma grande variação de animais, alimentos, manejo e condições ambientais.
Estes sistemas possuem submodelos para funções fisiológicas e metabólicas: consumo, fermentação de carboidratos e degradação de proteínas no rúmen, digestão e absorção intestinal, excreção, utilização e partição de nutrientes para mantença, crescimento, lactação e engorda.

O CNCPS desenvolvido por Fox et al. (1992) adotou o fracionamento dos carboidratos e proteínas, que, associados a estimativas da dinâmica do processo, pode predizer com maior precisão a performance dos animais e estimar a quantidade de proteína microbiana sintetizada e o escape ruminal de nutrientes. Com isso, determina-se energia e proteína metabolizável a partir dos dados relativos às frações de carboidratos e proteínas e de suas taxas de degradação.

O NRC (1996) também utiliza o fracionamento da proteína e carboidratos dos alimentos, a exemplo do CNCPS, porém estes dois sistemas são oriundos de países de clima temperado e utilizam tabelas cujos alimentos apresentam composição química distinta daqueles existentes no Brasil. Outro aspecto é que, tanto para o CNCPS quanto para o NRC nível 1 , as exigências dos animais estão baseadas em raças britânicas, portanto, precoces em maturação e com peso de abate ideal fixado em $450 \mathrm{~kg}$, sendo os demais grupos genéticos avaliados por intermédio de fatores de correção para exigências nutricionais em relação ao padrão pré-definido. Dessa forma, além do estudo da composição dos alimentos, a avaliação de raças e cruzamentos de bovinos criados

Tabela I. Dados meteorológicos do período experimental. (Meteorological data of the experimental period).

\begin{tabular}{lcccccc}
\hline & Julho & Agosto & Setembro & Outubro & Novembro & Dezembro \\
\hline Precipitação* $^{*}$ & 0,0 & 0,0 & 23,2 & 102,0 & 219,8 & 206,2 \\
Temperatura $\left({ }^{\circ} \mathrm{C}\right)^{* *}$ & 19,3 & 22,1 & 24,8 & 25,7 & 25,3 & 24,5 \\
Umidade relativa do ar $(\%)^{* *}$ & 63,0 & 52,0 & 51,0 & 64,0 & 71,0 & 73,0 \\
\hline
\end{tabular}

*Acumulado no período (mm); **média diária; Fonte: estação evaporimétrica de Goiânia, 2008. 


\section{MODELOS PARA PREDIÇÃO DE CONSUMO E GANHO EM PESO DE BOVINOS}

no Brasil é importante para a evolução de sistemas nacionais de formulação de dietas.

Visando validar a utilização de modelos matemáticos em condições tropicais brasileiras de confinamento, realizou-se este estudo com o objetivo de comparar os consumos e ganhos em peso observados com os preditos pelo CNCPS e NRC nível 1.

\section{MATERIALEMÉTODOS}

O experimento foi conduzido durante 136 dias no período compreendido entre Agosto e Dezembro de 2008, em área pertencente à Universidade Federal de Goiás (UFG), localizada no município de Goiânia, com altitude de $2367 \mathrm{~m}$, latitude $16^{\circ} 35^{\prime} \mathrm{Sul} \mathrm{e}$ longitude $49^{\circ} 17^{\prime}$ Oeste. O clima é classificado, segundo Koppen, como AW, tropical úmido, com estação chuvosa de outubro a março e seca de abril a setembro. Os índices de precipitação acumulada, temperatura e umidade relativa do ar do período experimental estão apresentados na tabela I.

O consumo de matéria seca (CMS) e o ganho em peso médio diário (GMD) dos novilhos em confinamento foram avaliados em dois tratamentos, TA e TM, com níveis de 80 e $50 \%$ de inclusão de concentrado na matéria seca (MS) da dieta, respectivamente, fornecida diariamente duas vezes, ás 8:00 e 17:00 horas.

Foram utilizados 23 novilhos mestiços Holandês/Zebu castrados, de mesma origem, adquiridos de fazendas da região, com vinte meses de idade, peso médio de $264 \mathrm{~kg}$ e 6 pontos de escore de condição corporal (ECC) avaliado em escala de 1 a 9 em que o índice 1 representa o animal muito magro e 9 muito gordo.

Os animais foram confinados em baias individuais parcialmente cobertas com 1,8 $\mathrm{m}$ de largura e 4,0 $\mathrm{m}$ de comprimento com acesso permanente ao cocho e bebedouro. Antes do período de adaptação, os animais foram pesados, identificados com brincos, tratados contra ecto e endoparasitas. Durante o período de adaptação de 14 dias, foram alimentados à vontade com inclusão gradual de concentrado na dieta. Após o período de adaptação, foram submetidos ao ensaio de alimentação, sendo distribuídos nas baias, individualmente, alimentados a vontade com fornecimento de ração ajustado de forma a permitir $10 \%$ de sobras em função das dietas experimentais apresentadas na tabela II. Os animais permaneceram confinados até que atingissem peso de abate pré estabelecido de $400 \mathrm{~kg}$.

As amostras de alimentos e sobras foram congeladas e posteriormente, foram présecas em estufa de ventilação forçada, a $65^{\circ} \mathrm{C}$ por 72 horas, moídas em peneira de malha de $1 \mathrm{~mm}$ e submetidas às análises laboratoriais. A composição química e bromatológica dos alimentos utilizados pode ser observada na tabela III. As determinações de matéria seca (MS), matéria

Tabela II. Proporção dos ingredientes na matéria seca das rações experimentais em função dos tratamentos. (Proportions of ingredients of experimental diets according treatments).

\begin{tabular}{lcccc}
\hline Ingredientes (\%) & Tratamentos & TA & \multicolumn{2}{c}{ Códigos no banco de dados } \\
& TM & NRC & CNCPS \\
\hline Silagem de sorgo & 50,00 & 20,00 & 321 & 15014 \\
Milho grão moído & 29,00 & 66,40 & 409 & 1039 \\
Farelo de soja & 18,50 & 11,60 & 517 & 2026 \\
Ureia & 0,50 & 0,40 & 522 & 2039 \\
Premix mineral & 2,00 & 1,60 & 999 & 5050 \\
\hline
\end{tabular}

TM: médio nível de inclusão de concentrado na dieta; TA: alto nível de inclusão de concentrado na dieta. 
Tabela III. Composição química e bromatológica dos alimentos utilizados expressa em percentual da matéria seca. (Chemical composition of foods used expressed in percentage of dry matter).

\begin{tabular}{lccccr}
\hline & \multicolumn{2}{c}{ Concentrado } & \multicolumn{2}{c}{ Volumoso } & Dieta total \\
\% Nutrientes & TM & TA & TM & TA & MS \\
\hline & 85,90 & 85,75 & 25,56 & 55,73 & 79,75 \\
Proteína bruta & 24,77 & 17,91 & 7,63 & 16,20 & 16,57 \\
FDN & 13,69 & 13,38 & 59,20 & 36,44 & 17,99 \\
FDA & 7,14 & 4,60 & 38,60 & 22,87 & 8,26 \\
Extrato etéreo & 2,63 & 2,21 & 1,90 & 2,27 & 2,22 \\
Cinzas & 7,45 & 4,45 & 3,81 & 5,63 & 4,68 \\
\hline
\end{tabular}

TM: médio nível de inclusão de concentrado na dieta; TA: alto nível de inclusão de concentrado na dieta; MS: matéria seca; FDA (fibra em detergente ácido); FDN (fibra em detergente neutro).

orgânica (MO), nitrogênio total, extrato etéreo (EE), fibra em detergente neutro (FDN) e fibra em detergente ácido (FDA) dos alimentos e das sobras foram realizadas conforme Silva (2002), sendo a proteína bruta (PB) obtida pelo produto entre o teor de nitrogênio total e o fator 6,25 .

As dietas eram isonitrogenadas e o volumoso utilizado em ambos os tratamentos foi silagem de sorgo (Sorghum bicolor L. Moench) sendo que o fornecimento do volumoso e concentrado foi realizado de maneira concomitante, misturados imediatamente antes do fornecimento. Visando contornar possíveis distúrbios metabólicos em função da alta inclusão de concentrado na dieta do tratamento TA, foi incluído ionóforos (monensina sódica) na dieta. A dieta foi reajustada semanalmente com base no consumo alimentar e no teor de MS do volumoso e do concentrado. A determinação do consumo de matéria seca observado foi realizada diariamente de forma individual pela pesagem da ração no momento do fornecimento e das sobras no dia subseqüente.

O ganho em peso médio diário observado foi determinado em intervalos de 21 dias através da pesagem dos animais após jejum de 12 horas, calculados pela diferença entre o peso posterior e o anterior, divido pelo número de dias contido no período compreendido entre as duas pesagens. $\mathrm{O}$ período.

Foram utilizados os modelos Cornell Net Carbohydrate and Protein System (CNCPS) e National Research Council (NRC) nível 1 para estimar o ganho em peso médio diário predito e o consumo de matéria seca predito. Os dados utilizados como entrada nos sis-

Tabela IV. Resumo dos dados de entrada dos animais e das condições ambientais utilizados nos sistemas CNCPS e NRC. (Summary of the data entry of animals and environmental conditions used by CNCPS systems and NRC).

\begin{tabular}{lccccc}
\hline IA (meses) & PVI (kg) & PM 27\% (kg) & ECC (1 - 9) & Temp. ( $\left.{ }^{\circ} \mathrm{C}\right)$ & UR (\%) \\
\hline 20 & 264 & 450 & 6 & 24 & 60 \\
\hline
\end{tabular}

IA: idade inicial; PVI: peso vivo inicial; PM: peso maduro com 27\% de gordura; ECC: escore de condição corporal; Temp.: temperatura; UR: umidade relativa do ar. 
temas de formulação CNCPS e NRC encontram-se na tabela IV.

A validação das equações do NRC e do CNCPS para estimativa GMD e CMS foi avaliada com auxilio do procedimento PROC REG do pacote estatístico SAS (2002) a partir da comparação dos valores observados com os valores estimados por meio das equações. O procedimento de validação foi feito por intermédio do ajuste de modelo de regressão linear simples dos valores preditos sobre os observados, de acordo com o seguinte modelo:

$$
Y_{i}=B_{1} x_{i}+e_{i}
$$

em que:

$\mathrm{Y}_{\mathrm{i}}=$ valor predito;

$\mathrm{B}_{1}=$ coeficiente de inclinação da reta;

$\mathrm{x}_{\mathrm{i}}=$ valor observado;

$\mathrm{e}_{\mathrm{i}}=$ erro aleatório, associado a cada observação.
Realizou-se ainda análise de comparação de médias entre os valores observados e preditos pelo teste $t$.

A estimativa do parâmetro $B_{1}$ da equação de regressão foi testada sobre as seguintes hipóteses: $\mathrm{H}_{0}: \mathrm{B}_{1} \neq 1$ e $\mathrm{H}_{1}: \mathrm{B}_{1} \neq 1$. Quando da não-rejeição da hipótese de nulidade, os valores preditos e observados são similares, enquanto, no caso da rejeição da hipótese de nulidade, verificou-se a presença do vício global de estimação (VGE). O vício global de estimação é estimado como:

$$
\text { VGE }=\left(B_{1}-1\right) \times 100
$$

em que:

$\mathrm{B}_{1}=$ estimativa do coeficiente angular da equação de regressão sem intercepto e

$1=$ valor paramétrico para o coeficiente angular sob a pressuposição de $\mathrm{H}_{0}$ ser verdadeira.

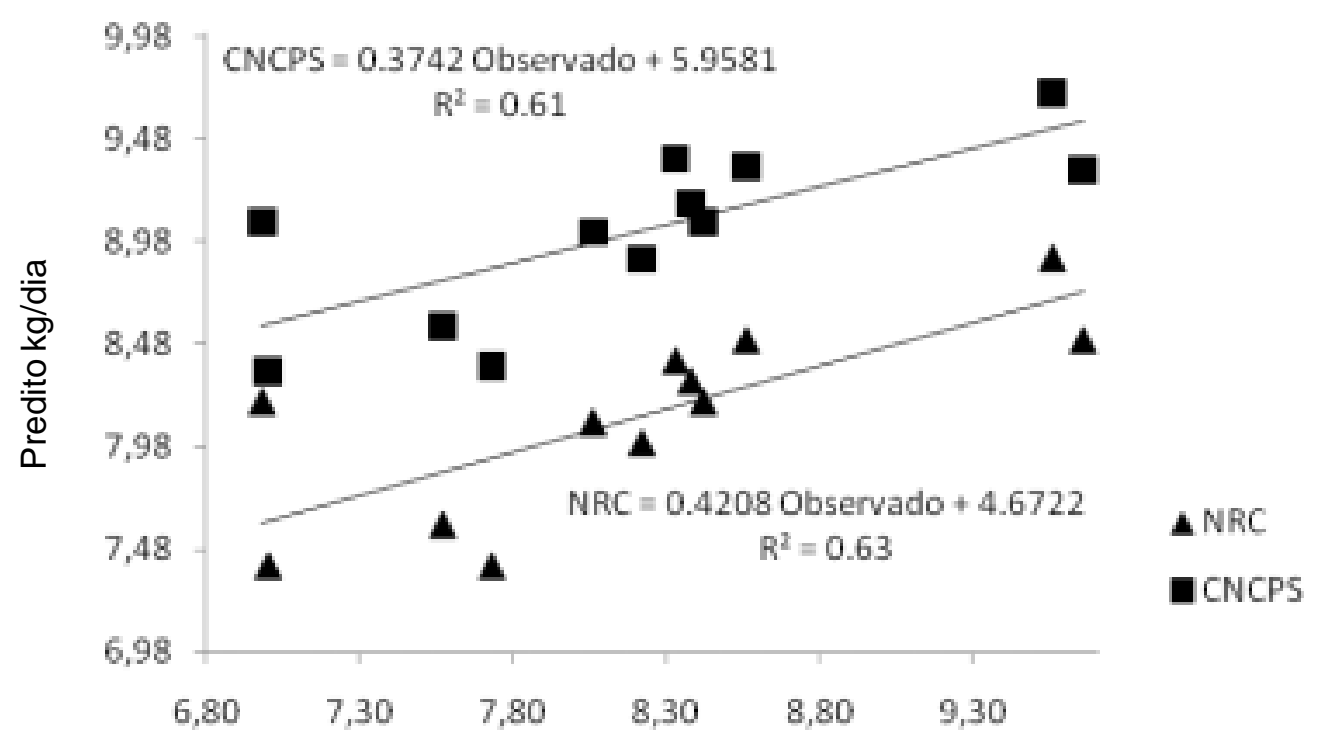

Observado kg/dia

Figura 1. Relação entre os consumos observados e preditos pelo CNCPS e NRC para o nível médio de alimentação (TM). (Relationship between observed and predicted consumption by CNCPS and $\mathrm{NRC}$ to the medium feeding level (TM)). 


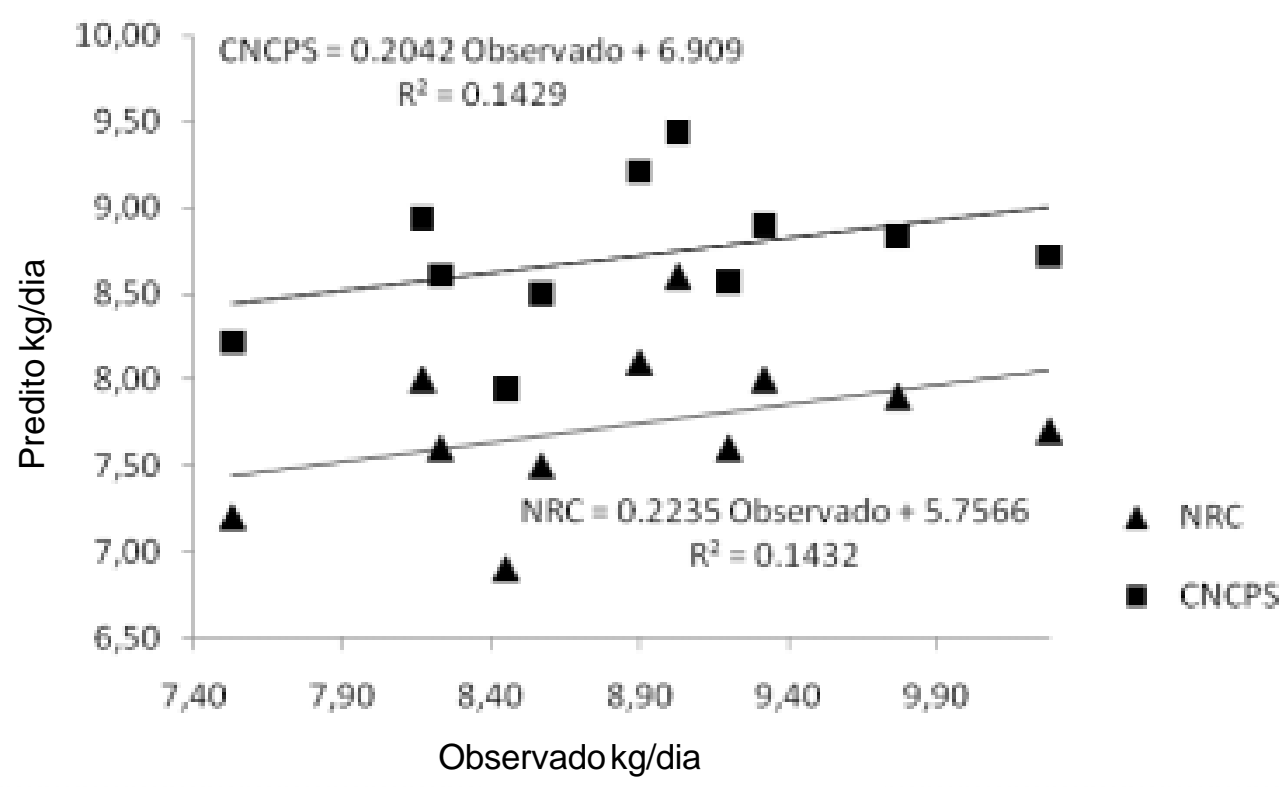

Figura 2. Relação entre os consumos observados e preditos pelo CNCPS e NRC para o nível alto de alimentação. (Relationship between observed and predicted consumption by CNCPS and NRC to the high feeding level (TM)).

Para todos os procedimentos estatísticos descritos, adotou-se 5\% como nível de significância máximo.

\section{RESULTADOSEDISCUSSÃO}

\section{CONSUMODE MATÉRIA SECA}

Na tabela $\mathbf{V}$, são apresentados os valores médios de CMS observados no experimento e os valores preditos pelo NRC e CNCPS. Os valores foram agrupados em função dos tratamentos.

Verificou-se em relação ao tratamento alimentar médio, que consistiu de volumoso e concentrado em proporções iguais, que houve subestimação e superestimação para a predição de CMS pelos modelos NRC e CNCPS, respectivamente, entretanto os coeficientes de regressão linear demonstraram que as predições mais acuradas ocorreram com este tratamento $(50 \%$ de concentrado) para ambos os modelos mate- máticos como demonstrado na figura 1.

Obteve-se a equação de regressão linear entre os consumos observados e preditos pelo modelo de Cornell:

$$
\begin{aligned}
& \text { CNCPS }(T M)=0,3742 \text { Observado }+5,9581 \\
& \left(R^{2}=0,61 ; p<0,05\right)
\end{aligned}
$$

e pelo National Research Council:

$$
\begin{aligned}
& \operatorname{NRC}(T M)=0,4208 \text { Observado }+4,6722 \\
& \left(R^{2}=0,63 ; p<0,05\right)
\end{aligned}
$$

Avaliando as predições de consumo de ambos os modelos no tratamento médio, constatou-se pelo teste $t$, que $B_{1} \neq 1$ e que $B_{0} \neq$ 0 , o que indica que a inclinação da reta obtida pela regressão é semelhante à da reta ideal $(\mathrm{Y}=\mathrm{X})$, significando que o CNCPS e o NRC foram adequados para predizer o consumo de matéria seca dos animais nestas condições alimentares (figura 1).

Em relação ao regime alimentar com alta 
Tabela V. Consumo de matéria seca e ganho em peso médio diário observado e predito pelas equações do NRC e CNCPS. (Dry matter intake and daily weight gain observed and predicted by NRC and CNCPS equations ).

\begin{tabular}{cccc}
\hline & \multicolumn{3}{c}{ Consumo de matéria seca (kg/dia) } \\
& NRC & CNCPS & Observado \\
TM & $8,13^{\mathrm{a}}$ & $9,03^{\mathrm{a}}$ & $8,21^{\mathrm{a}}$ \\
TA & $7,74^{\mathrm{b}}$ & $8,72^{\mathrm{b}}$ & $8,86^{\mathrm{a}}$ \\
& \multicolumn{2}{c}{ Ganho em peso médio diário (kg/dia) } \\
& NRC & CNCPS & Observado \\
TM & $1,12^{\mathrm{b}}$ & $1,26^{\mathrm{b}}$ & $1,33^{\mathrm{a}}$ \\
TA & $1,31^{\mathrm{b}}$ & $1,52^{\mathrm{a}}$ & $1,45^{\mathrm{b}}$ \\
\hline
\end{tabular}

TM: Médio nível de inclusão de concentrado na dieta; TA: Alto nível de inclusão de concentrado na dieta. Letras diferentes na linha indicam diferença estatística $(p<0,05)$ pelo teste $t$ entre os valores preditos pelos modelos e os observados.

inclusão de concentrado (80\%) observouse que ambos os modelos subestimaram $(\mathrm{p}<0,05)$ o consumo de matéria seca. Os coeficientes de regressão linear sugerem que, nas condições experimentais avaliadas, ambos os modelos não foram eficientes para predizer o CMS para este tratamento como demonstrado na figura 2 .

Cappelle et al. (2001) ao compilar resultados de sete ensaios de alimentação para validação do CNCPS em condições brasileiras, observaram que este modelo foi eficiente para predizer o CMS de bovinos em confinamento, confirmado pela equação de regressão linear entre os consumos observados e preditos pelo CNCPS:

$$
\begin{aligned}
& \text { YOBS }=2,27107+0,967479 \times C N C P S \\
& \left(R^{2}=0,92 ; p<0,01\right)
\end{aligned}
$$

Estes resultados divergem do estudo de Véras et al. (2000) que verificaram que os CMS obtidos foram maiores que os preditos para tratamentos cujos níveis de concentrado foram de $25 ; 37,5 ; 50 ; 62,5$ e $75 \%$ e não seguiram o comportamento da relação ideal,

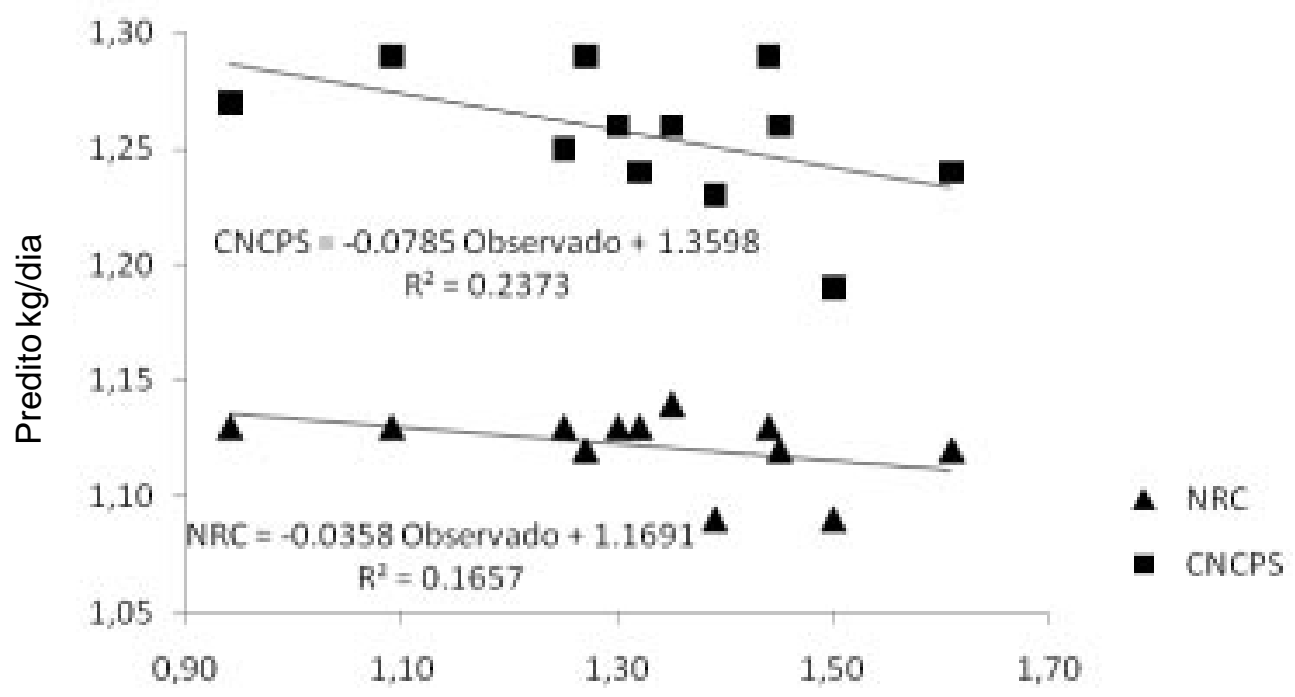

Observado kg/dia

Figura 3. Relação entre ganho em peso médio diário observado e predito pelo CNCPS e NRC para o nível médio de alimentação (TM). (Relationship between average daily weight gain observed and predicted by the NRC and CNCPS to the medium feeding level (TM)). 
sugerindo que o CNCPS não foi adequado para predizer a ingestão de MS.

Gesualdi Jr. et al. (2005) avaliando a utilização do NRC e do CNCPS, com dietas de igual proporção de volumoso e concentrado para bovinos de diferentes grupos genéticos em condições tropicais de confinamento, concluíram que ambos os modelos foram eficientes $(p>0,10)$ para predizer o consumo de matéria seca. O consumo de dietas com alta densidade calórica é definido pela demanda energética do animal. Véras et al. (2000) verificaram que, com a inclusão de concentrado em níveis superiores a $50 \%$ na dieta, a ingestão de MS foi limitada pela demanda energética do animal. CSIRO (1990) definiu o potencial de ingestão de alimentos como a quantidade de alimento ingerido quando oferecido á vontade e o animal é capaz de selecionar uma dieta com uma digestibilidade da MS de pelo menos $80 \%$ ou com uma concentração de pelo menos 2,6 Mcal $/ \mathrm{kg}$ de MS (11 MJ EM/kg de
MS). Esse comitê adotou para os cálculos de ingestão de MS o peso à maturidade relativo (peso corporal atual/peso corporal a maturidade), indicando que o pico de ingestão ocorre quando o tamanho relativo for 0,85 .

Nos sistemas CNCPS e NRC, os valores de energia da ração são obtidos pelo somatório da contribuição de energia de cada ingrediente alimentar para alcançar o conteúdo total de energia da dieta, utilizando-se valores tabulares. Os valores de energia são preditos a partir das propriedades químicas e físicas dos alimentos que estão relacionadas ao nível de processamento dos alimentos concentrados que é muito variável explicando, em parte, a ineficiência de ambos os modelos para predição do CMS no regime alimentar de alta inclusão de concentrado.

\section{GANHOEMPESOMÉDIODIÁRIO}

Comparando os ganhos em peso ob-

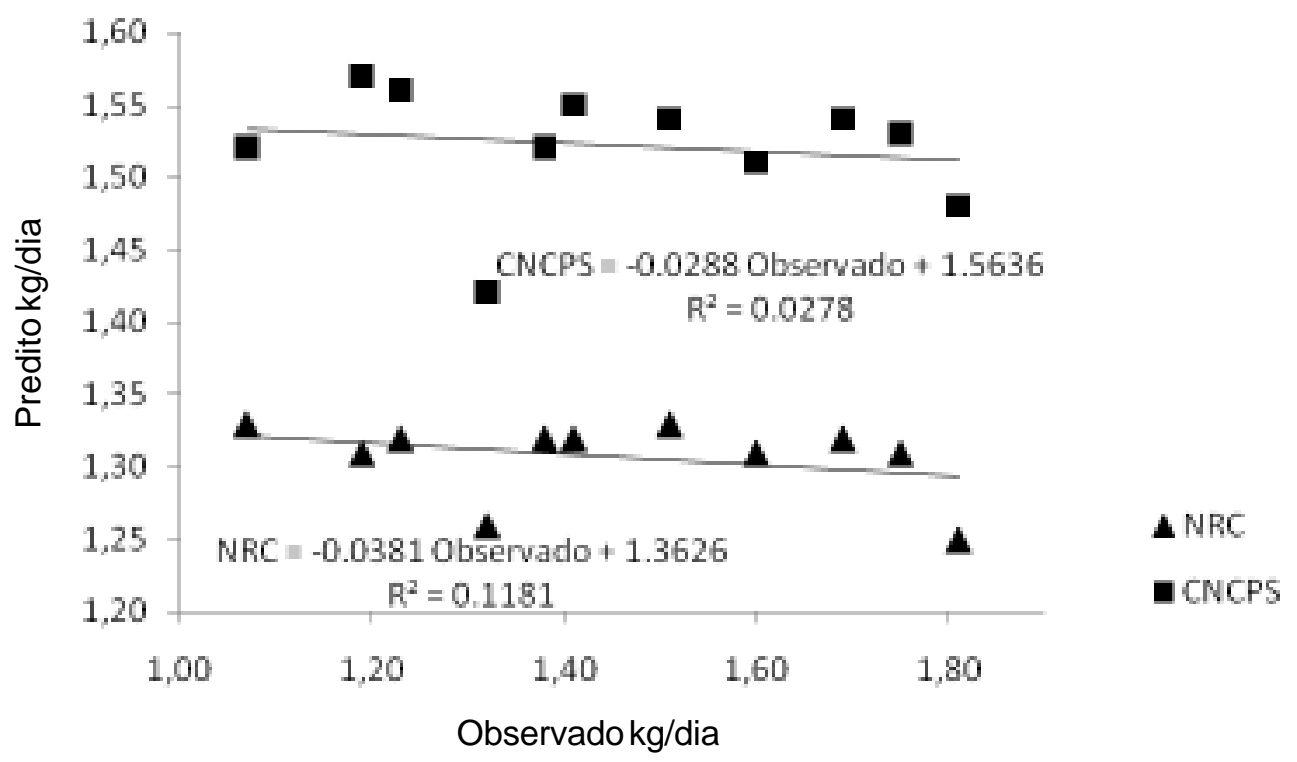

Figura 4. Relação entre ganho em peso médio diário observado e predito pelo CNCPS e NRC para o nivel alto de alimentação (TA). (Relationship between average daily weight gain observed and predicted by the NRC and CNCPS to the high feeding level (TA)). 


\section{MODELOS PARA PREDIÇÃO DE CONSUMO E GANHO EM PESO DE BOVINOS}

servados e os preditos de acordo com a disponibilidade de energia metabolizável estimada pelos modelos, constatou-se que houve subestimação e superestimação para o NRC e CNCPS, respectivamente para o tratamento alto nível de concentrado. Com relação ao tratamento médio, ambos os modelos subestimaram o ganho em peso médio diário ( $\mathrm{kg} / \mathrm{dia})$.

Os ganhos em peso observados apresentaram grandes variações, quando comparados aos preditos, obtendo valores iguais e até $77 \%$ maiores. As melhores predições de ganho em peso foram para o tratamento médio, constituído por volumoso e concentrado em proporções iguais, em que se obteve a equação de regressão linear entre os ganhos preditos e observados pelos modelos como demonstrado na figura 3:

$$
\begin{aligned}
& \mathrm{NRC}(\mathrm{TM})=-0,0358 \text { Observado }+1,1691 \\
& \left(R^{2}=0,16\right) \\
& \mathrm{C} \quad \begin{array}{l}
\text { CNCPS }(\mathrm{TM})=-0,0785 \text { Observado }+1,3598 \\
\left(\mathrm{R}^{2}=0,24\right)
\end{array}
\end{aligned}
$$

Verificou-se que, para o tratamento alto ( $80 \%$ de concentrado), o GMD apresentou as maiores variações com relação à estimativa do CNCPS e NRC, o que poderia indicar que, com grandes quantidades de concentrado, os modelos não forneceram boa predição para os animais analisados em condições tropicais de confinamento. Obtiveram-se as equações de regressão linear entre os ganhos de peso observados e preditos:

$$
\begin{aligned}
& \text { CNCPS }(T A)=-0,0288 \text { Observado }+1,5636 \\
& \left(R^{2}=0,02 ; p>0,05\right) \\
& N R C(T A)=-0,0381 \text { Observado }+1,3626 \\
& \left(R^{2}=0,11 ; p>0,05\right)
\end{aligned}
$$$$
\mathrm{e}
$$

Constatou-se pelo teste $\mathrm{t}$, que $\mathrm{B} 1 \neq 1$ e que $\mathrm{B} 0 \neq 0$, o que indica que a inclinação da reta obtida pela regressão apresenta tanto inclinação como intercepto diferentes da reta ideal $(Y=X)$ como demonstrado na figura 4.

As diferenças significativas $(\mathrm{p}<0,05)$ verificadas entre os valores de ganho em peso observados e preditos por ambos os modelos, endossam os estudos de Cappelle et al. (2001) que mencionam que a amplitude dessas diferenças pode estar relacionada à alimentação, ao efeito genético, à idade de abate, à condição sexual, entre outras características que devem ser consideradas, quando se pretende utilizar o NRC ou CNCPS como ferramentas para estimar o ganho em peso médio diário.

Perotto et al. (2001) encontraram efeito de mês e de ano de nascimento, além de efeito de animal dentro de uma mesma raça, ao avaliarem o ganho de peso da desmama aos 12 meses e o peso aos 12 meses de idade de bovinos Nelore e cruzados. A estes fatores, acrescentam-se os efeitos interativos e de ganho compensatório que ainda não foram incorporados de maneira eficiente nos modelos de formulação de dietas, mas certamente influenciam o desempenho animal em condições de confinamento.

Segundo Gesualdi Jr. et al. (2005) o ganho compensatório, fenômeno muito comum em rebanhos de países de clima tropical e mais raro em climas temperados, também pode contribuir para a ocorrência de simulações que subpredizem o ganho em peso esperado. Entretanto, a extensão do ganho compensatório, se nulo, parcial ou completo é de difícil predição.

Diante dos resultados insatisfatórios para a predição do desempenho dos animais em ambos os tratamentos, faz-se necessário maior número de pesquisas no sentido de adequar estes modelos aos fatores genéticos e ambientais e às características físico-químicas dos alimentos utilizados no Brasil.

\section{CONCLUSÕES}

Os sistemas de formulação de dietas estudados foram eficientes para predição 
de ingestão diária de matéria seca de dietas compostas por volumoso e concentrado em proporções iguais, mas não predisseram acuradamente o consumo das dietas com alta inclusão de concentrado.

Aparentemente os sistemas estudados

\section{BIBLIOGRAFIA}

Capelle, E.R., Valadares Filho, S.C., Coelho da Silva, J.F. e Cecon, P.R. 2001. Estimativas do consumo e do ganho de peso de bovinos, em condições brasileiras. Rev. Bras. Zootecn., 30: 659-957.

CSIRO. 1990. Commonwealth scientific and industrial research organization. Feeding standards for Australian livestock. Ruminants. Australia Agricultural Council. Victoria. 266 pp.

Fox, D.G., Sniffen, C.J., O'connor, J.D., Russell, J.B. and Van Soest, P.J. 1992. A net carbohydrate and protein system for evaluating cattle diets: III. Cattle requirements and diet adequacy. J. Anim. Sci., 70: 3578-3596.

Gesualdi Jr., A.G., Queiroz, A.C., Resende, F.D., Lana, R.P., Gesualdi, A.C.L.S., Alleoni, G.F., Detmann, E., Razook, A.G. e Figueiredo, L.A. 2005. Validação dos sistemas VIÇOSA, CNCPS e NRC para formulação de dietas para bovinos Nelore e Caracu, não-castrados, selecionados em condições brasileiras. Rev. Bras. Zootecn., 34: 997-1005.

Gill, M., Beever, D.E. and France, J. 1989. Biochemical bases needed for the mathematical representation of whole animal metabolism. Nutr. Abstr. Rev., 2: 181-200. necessitam de ajustes para sua utilização acurada em sistemas de produção de animais mestiços em condições tropicais de confinamento, fato evidenciado principalmente, pelas sub e superestimativas do ganho em peso.

NRC. 1996. Nutrient requirements of beef cattle. $7^{\mathrm{a}}$ ed. National Academy Press. Washington, DC. $242 \mathrm{pp}$.

Perotto, D., Cubas, A.C., Abrahão, J.J.S. e Mella, S.C. 2001. Ganho de peso da desmama aos 12 meses e peso aos 12 meses de bovinos nelore e cruzas com Nelore. Rev. Bras. Zootecn., 30: 730-734.

SAS Institute. 2002. SAS/STAT User's guide: Statistics. 6 ${ }^{a}$ ed. V. 8. Cary, NC. V. 2. 943 pp.

Silva, D.J. e Queiroz, A.C. 2002. Análise de alimentos (métodos químicos e biológicos). $3^{\mathrm{a}} \mathrm{ed}$. Universidade Federal de Viçosa. Viçosa, MG. $235 \mathrm{pp}$.

Tedeschi, L.O., Fox, D.G., Sainz, R.D., Barioni, L.G., Medeiros, S.R. and Boin, C. 2005. Mathematical models in ruminant nutrition: Review. Sci. Agric., 62: 76-91.

Véras, A.S.C., Valadares Filho, S.C., Coelho da Silva, J.F., Fonseca Paulino, M., Cecon, P.R., Valadares, R.F.D., De Andrade Ferreira, M. e Da Silva Cabral, L. 2000. Consumo e digestibilidade aparente em bovinos Nelore, não castrados, alimentados com rações com diferentes níveis de concentrado. Rev. Bras. Zootecn., 29: 2367-2378. 